\title{
Rancangan Pembukuan Akuntansi Berbasis Excel for Accounting Pada Koperasi Jasa Keuangan Syariah (KJKS)
}

\author{
Novrina Chandra \\ Sukartini \\ Jurusan Akuntansi Politeknik Negeri Padang
}

\begin{abstract}
In order to increase the society empowerment, Government of Padang create a program PKBK$B M T$. This program is an integrated activity in order to accelerates poverty reduction, so that thegovernment of Padang form KJKS-BMT in every districts which aims to facilitates the poor society with microfinance and sustainable assistance, so that they can empower themselves. KJKS must convey accountability and financial reports activities to the local government. Therefore it needs accountable, accurate and timely financial statement. Both partners in these activities together are equaly have very good potential business development, but lack in the processing of financial transaction data and in the preparing of qualified financial statement for the decision making process of business development accountability. The results of this activitiy are the design of accounting bookkeeping based on excel for accounting, creating administrators who has ability to operate financial database, analizing and inputting financial transaction on the design of application. Beside, administrators can get the latest financial information at anytime by accessing that application design. The goals are to be known how far this program will run well and if there are some constraints encountered in the field then can immediately discussed with the administrators from both partners.
\end{abstract}

Keywords : KJKS-BMT, the design of accounting books, excel for accounting, financial statement

\section{PENDAHULUAN}

Dalam rangka meningkatkan pember-dayaan masyarakat, Pemerintah Kota Padang membuat sebuah program kerja yaitu Program Penanggulangan Kemis-kinan Berbasis Kelurahan Melalui Pengembangan BMT (PKBK-BMT). Program ini merupakan sebuah kegiatan terpadu dalam rangka mempercepat penanggulangan kemiskinan di Kota Padang. Untuk itu Pemerintah Kota Padang membentuk KJKS-BMT (Koperasi Jasa Keuangan Syariah Baitul Maal wat Tamwil) di setiap kelurahan yang bertujuan untuk menfasilitasi kelompok masyarakat miskindengan pembiayaan usaha mikro dan pendampingan berkelanjutan sehingga mampu memberdayakan dirinya sendiri.

Sebagai lembaga yang dibentuk oleh Pemerintah Kota Padang, maka KJKS harus menyampaikan pertanggung-jawaban setiap kegiatan dan pelaporan keuangan ke Pemerintah Kota. Berdasarkan Laporan
Keuangan yang dihasilkan oleh KJKS-BMT Pemerintah Kota Padang akan bisa mengambil keputusan untuk pengembangan KJKS-BMT. Untuk itu perlu dihasilkan laporan keuangan yang akuntabel, akurat dan tepat waktu.

KJKS-BMT adalah Koperasi Jasa Keuangan Syariah Baitul Maal wat Tamwil yaitu sistem intermediasi keuangan di tingkat mikro yang berbadan hukum koperasi yang didalamnya terdapat Baitul Maal dan Baitul Tamwil yang dalam operasionalnya dijalankan dengan menerapkan prinsip-prinsip syari'ah.

\section{Kondisi Mitra}

Mitra terdiri dari 2 kelompok yaitu KJKS-BMT Kampung Lapai dan KJKS-BMT Surau Gadang Siteba. Kedua KJKS-BMT ini berada di kota Padang Sumatera Barat. KJKS-BMT Kampung Lapai didirikan pada bulan Juli 2011 tetapi baru beroperasi bulan Januari 2012. Hal ini dikarenakan untuk persiapan modal penyertaan dan pengurus yang 
melibatkan pemuka masyarakat di daerah KJKS tersebut. Lokasi dari KJKS-BMT Kampung Lapai adalah Keluarga Kampung Lapai Jalan Kesehatan I No. 5 RT 001/RW 001 Padang. Berjarak $\pm 14,7 \mathrm{~km}$ dari kampus Politeknik Negeri Padang. KJKS-BMT Kampung Lapai ini dikelola oleh seorang manajer yaitu Bapak Nahri Pebriadi, S.Kom dan dibantu oleh satu orang untuk pembukuan yang bernama Revina Berliani, S.Pd. Struktur organisasi dari KJKS-BMT Kampung Lapai ini terdiri dari beberapa pengurus, pembina, badan pengawas, pendamping, manajer dan pembukuan. Untuk pengurus ada 5 orang, pembina yaitu lurah di lokasi KJKS-BMT, badan pengawas ada 3 orang sedangkan pendamping ada 1 orang. Pendamping maksudnya disini adalah orang yang melakukan pembinaan untuk KJKS-BMT. Modal awal KJKS-BMT Kampung Lapai berasal dari pendiri 30 orang warga Kampung Lapai berjumlah sebesar Rp 20.000.000,- dan pengalihan dana kredit mikro kelurahan pada awalnya sebesar $\mathrm{Rp}$ 40.000 .000 ,- sehingga total modal awal KJKS-BMT Kampung Lapai ini adalah sebesar Rp 60.000.000,-. Tetapi setelah KJKS-BMT ini beroperasi kredit mikro kelurahan tetap diusahakan ditagih sehingga total pengalihan kredit mikro kelurahan sampai sekarang berjumlah $\operatorname{Rp} 70.000 .000$,Pengelola dari KJKS-BMT ini digaji oleh pemerintah daerah dimana gaji manajer sebesar Rp 1.000.000,- dan gaji bagian pembukuan sebesar Rp 700.000,-. Disamping itu KJKS-BMT ini juga memberikan uang transport sebesar Rp $100.000 /$ bulan. Fasilitas yang ada pada KJKS-BMT Kampung Lapai ini terdiri dari meja, kursi dan laptop sebanyak 1 (satu) buah, tetapi laptop ini sering dibawa oleh manajer sehingga bagian pembukuan hanya mencatat setiap kegiatan hariannya dalam buku. Semua aktivitas yang dilakukan oleh KJKS-BMT Kampung Lapai menggunakan salah satu ruangan di lantai 2 komplek Mesjid Buturahman. Kegiatan yang dilakukan oleh KJKS-BMT Kampung Lapai adalah pembiayaan murabahah. Anggota KJKSBMT ini berjumlah sebanyak 47 orang dengan 7 kelompok, dimana 1 kelompok ini jumlahnya bervariasi, ada yang terdiri dari 5 sampai 7 orang. Pada waktu awal berdiri KJKS-BMT Kampung Lapai memberikan pembiayaan berdasarkan perkelompok dimana setiap anggota kelompok hanya diberikan $\mathrm{Rp} 1.000 .000$,- dengan tenor 3 bulan, kemudian pemberian pembiayaan ditingkatkan menjadi Rp 3.000.000,- per orang dengan tenor 6 bulan tetapi berdasarkan hasil rapat tahunan kemarin diputuskan untuk memperpanjang jangka waktu pembiayaan menjadi 10 bulan.

Sedangkan KJKS-BMT Surau Gadang Siteba terletak di Jalan Padang No. 1 Kelurahan Surau Gadang Kecamatan Nanggalo Padang. Berjarak $\pm 13,5 \mathrm{~km}$ dari kampus Politeknik Negeri Padang Didirikan pada bulan Juli 2011 dan baru beroperasi bulan Januari 2012. Keterlambatan beroperasinya KJKS-BMT Surau Gadang ini dikarenakan untuk mempersiapkan modal penyertaan dan pengurus, dimana pengurus ini melibatkan pemuka masyarakat di daerah KJKS tersebut. Modal awal KJKS-BMT Surau Gadang berasal dari pendiri 20 orang warga Surau Gadang berjumlah sebesar Rp 21.700.000,- dan pengalihan dana kredit mikro kelurahan sebesar Rp 170.000.000,sehingga total modal awal KJKS-BMT Kampung Lapai ini adalah sebesar Rp 191.700.000,-. Tetapi setelah KJKS-BMT ini beroperasi kredit mikro kelurahan tetap diusahakan ditagih sehingga total pengalihan kredit mikro kelurahan sampai sekarang berjumlah $\mathrm{Rp} 210.000 .000,-$. Struktur organisasi dari KJKS-BMT Surau Gadang ini terdiri dari pengurus, pengawas, pengelola dan pendamping. Untuk pengurus ada 3 orang (ketua, sekretaris dan bendahara), pengawas ada 3 orang (lurah, LPM (Lembaga Pemberdayaan Masya-rakat) dan tokoh masyarakat), pengelola ada 2 orang (manajer dan pembukuan), sedangkan pendamping ada 1 orang. Pendamping maksudnya disini adalah orang yang melakukan pembinaan untuk KJKS-BMT dan untuk kedua KJKS ini pendampingnya sama yaitu Bapak Aprinoriza. KJKS-BMT Surau Gadang ini dikelola oleh seorang manajer yang bernama Betymes Enjumera Laila Salmi, SE, MM dan seorang bagian pembukuan Refina Nengsih, SE. Fasilitas yang ada pada KJKS-BMT Surau Gadang ini terdiri dari meja, kursi dan laptop sebanyak 1 (satu) buah. Karena latar belakang pendidikan bagian pembukuan adalah sarjana akuntansi sehingga pembukuan akuntansinya sudah sedikit rapi tapi masih manual karena laptop yang ada sering dibawa oleh manajer. Kegiatan yang 
dilakukan oleh KJKS-BMT Surau Gadang sama dengan KJKS sebelumnya yaitu pembiayaan murabahah. Anggota KJKSBMT ini berjumlah sebanyak 100 orang dengan 15 kelompok, dimana 1 kelompok ini jumlahnya bervariasi, ada yang terdiri dari 5 sampai 7 orang. Pada waktu awal berdiri KJKS-BMT Surau Gadang memberikan pembiayaan berdasarkan perkelompok dimana setiap anggota kelompok maksimal hanya diberikan $\mathrm{Rp} 6.000 .000$ per orang, itupun tergantung dari kemampuan dalam melunasi pembiayaan, tetapi dengan adanya peningkatan dana maka KJKS-BMT Surau Gadang berencana untuk memberikan pembiayaan secara perorangan minimal Rp 15.000.000 per orang. Jangka waktu pembiayaan yang mereka berikan adalah 10 (sepuluh) bulan, hal ini berbeda dengan KJKS-BMT Kampung Lapai karena dana yang diberikan jauh lebih besar.

\section{Potensi dan Peluang Usaha}

Potensi yang dimiliki oleh kelompok KJKSBMT ini adalah mereka sudah mempunyai anggota yang cukup banyak dan kelompok yang bertambah serta dana yang diberikan untuk pembiayaan juga semakin besar. Hal ini sangat membantu sekali terhadap keluarga miskin yang ada di sekitar KJKSBMT tersebut. Dengan dana yang mereka kelola sudah semakin besar seharusnya KJKS-BMT tersebut sudah mempunyai pembukuan yang lebih baik dalam mengelola keuangannya. Dengan keterbatasan yang dimiliki oleh kelompok KJKS-BMT ini maka mereka perlu dibekali dengan kemampuan mengelola keuangan dan administrasi agar dapat menghasilkan pelaporan pembukuan yang transparansi dan akuntabel. Salah satu bentuknya yaitu membuatkan rancangan pembukuan akuntansi berbasis excel for accounting bagi kelompok KJKS-BMT ini sehingga internal control terhadap keuangan usaha mitra ini menjadi lebih baik.

Berdasakan latar belakang diatas memotivasi tim pengabdian untuk membuat sebuah rancangan pembukuan keuangan dalam bentuk aplikasi excel for accounting yang nantinya akan bermanfaat bagi kedua mitra KJKS-BMT.

\section{Permasalahan Mitra}

Permasalahan operasional dalam KJKSBMT ini terletak pada proses pembukuan dan pembuatan laporan. Proses pembukuan yang tidak teratur dan tidak efisien memicu munculnya masalah operasional yang dapat menghambat perkembangan KJKS-BMT. Apabila KJKS-BMT tidak menanggapi masalah ini, KJKS-BMT akan mengalami kesulitan seiring dengan bertambahnya data yang harus ditangani sebagai konsekuensi bertambahnya anggota dan transaksi. Pada KJKS-BMT Kampung Lapai, manajer dan bagian pembukuannya tidak memiliki pengetahuan tentang akuntansi dan tidak memiliki kemampuan dalam pengelolaan keuangan, khususnya dalam administrasi dan penyusunan laporan keuangan. Sedangkan pada KJKS-BMT Surau Gadang, bagian pembukuannya yang sekarang sudah memiliki pengetahuan tentang akuntansi tetapi karena di tempat tersebut laptop sering dipakai oleh manajer untuk aktivitas yang lain sehingga pembukuan yang dilakukan masih secara manual yang menyebabkan sering terjadinya keterlambatan dalam memproses laporan keuangan harian. Petugas bagian pembukuan di KJKS-BMT yang sekarang baru menggantikan petugas lama yang sudah berhenti, sehingga ada beberapa data yang tidak cocok. Dengan ketidakcocokan data tersebut menyebabkan laporan tidak bisa disusun sehingga manajer berinisiatif meminta bantuan kepada pendamping. Pendamping memberikan solusi dengan menggunakan excel sederhana.

\section{METODE PELAKSANAAN}

Metode pelaksanaan kegiatan untuk kedua kelompok mitra KJKS-BMT Kampung Lapai dan KJKS-BMT Surau Gadang Sitebaadalah : (1) Membuatkan rancangan pembukuan akuntansi keuangan dengan menggunakan microsoft excel versi 2010; (2) Pemberian peralatan berupa; laptop, printer, dan software aplikasi excel for accounting dalam bentuk database laporan keuangan kepada masing-masing mitra kelompok KJKS-BMT; (3) Melakukan pengujian terhadap rancangan program database yang dibuat bersama dengan kedua mitra KJKS-BMT; (4) Implementasi terhadap rancangan program database yang dibuat bersama dengan 
kedua mitra KJKS-BMT; (5)Memberikan pelatihan, sosialisasi serta pendampingan kepada kedua mitra KJKS-BMT terhadap rancangan program pembukuan akuntansi yang dibuat sehingga kedua mitra tersebut dapat menyusun laporan keuangan; (6) Melakukan evaluasi terhadap rancangan program yang dibuat. Tujuannya agar diketahui sampai sejauh mana rancangan pembukuan akuntansi yang dibuat dapat berjalan dengan baik dan apabila ditemui kendala- kendala dilapangan maka langsung didiskusikan dengan pengelola dari kedua mitra kelompok KJKS-BMT ini.

Kegiatan dilaksanakan selama 8 (delapan) bulan terhitung kegiatan ini disetujui. Pertama sekali dilakukan survey lapangan kepada kedua kelompok mitra, sambil meminta data yang dibutuhkan untuk pembuatan rancangan program pembukuan akuntansi. Rancangan program dibuat di Politeknik Negeri Padang bersama dengan tim diperkirakan selama satu bulan. Setelah rancangan selesai dibuat maka tim langsung membuat program database laporan keuangan dalam bentuk aplikasi excel for accounting selama tiga bulan. Kemudian baru dilakukan pengujian dan implementasi dari program rancangan pembukuan tersebut serta dilakukan sosialisasi dalam bentuk pelatihan dan pendampingan cara menyusun laporan keuangan dengan menggunakan program yang sudah dibuat. Pelaksanaan pelatihan direncanakan dilakukan di tempat mitra tersebut karena masing- masing mitra mempunyai ruangan yang bisa dijadikan tempat pelatihan.

\section{HASIL DAN PEMBAHASAN}

Pelaksanaan kegiatan ini telah menyelesaikan beberapa tahap yaitu : (1) Membuatkan rancangan pembukuan akuntansi keuangan dengan menggunakan microsoft excel versi 2010; (2) Pemberian peralatan berupa; laptop, printer, harddisk external dan software aplikasi excel for accounting dalam bentuk database laporan keuangan kepada masing-masing mitra kelompok KJKS-BMT; (3) Melakukan pengujian terhadap rancangan program database yang dibuat bersama dengan kedua mitra KJKS-BMT.

\section{Partisipasi Mitra}

Mitra dalam hal ini adalah pengelola kelompok KJKS-BMT yaitu KJKS-BMT Kampung Lapai dan KJKS-BMT Surau Gadang. Partisipasi mereka dalam kegiatan ini adalah :Mendukung pembuatan program rancangan pembukuan akuntansi berbasis excel for accounting yang terkomputerisasi, memberikan informasi data dan informasi lainnya tentang persoalan yang mereka hadapi selama menjalankan KJKS-BMT tersebut, menunjuk peserta yang akan diikut sertakan dalam kegiatan ini berdasarkan penunjukan atau rekomendasi dari pimpinan KJKS-BMT Kampung Lapai dan KJKS-BMT Surau Gadang yang diberikan secara tertulis serta memberi motivasi, pengawasan dan pembinaan.

\section{Analisis Kebutuhan Sistem Informasi Akuntansi Mitra}

Berdasarkan kunjungan dan wawancara yang telah dilaksanakan dengan mitra, dapat disimpulkan bahwa : 1). Mitra belum memiliki sistem informasi yang memadai untuk memenuhi kebutuhan akan pelaporan keuangan yang baik (sesuai standar akuntansi); 2). Mitra belum memiliki kompetensi yang cukup menganalisis transaksi keuangan dan menyusun laporan keuangan; 3). Mitra memerlukan pelatihan yang memadai mengenai analisis transaksi, menjurnal transaksi dan menyusun laporan keuangan yang sesuai dengan standar akuntansi; 4). Mitra memerlukan perangkat hardware dan software rancangan program pembukuan akuntansi. Hardware berupa perangkat komputer dan printer untuk mencetak laporan, sedangkan software adalah aplikasi program pembukuan akuntansi yang dibuat dengan Microsoft Excel 2010 dengan tujuan agar mudah digunakan dan gampang untuk dilakukan perawatan (maintenance) di kemudian hari; 5). Mitra memerlukan pengetahuan dan keterampilan yang memadai untuk memperbaiki manajemen dengan tujuan untuk mampu bersaing dan meningkatkan omzet penjualan jasa yang ditawarkan.

\section{Perancangan Aplikasi Program Pembukuan Akuntansi Mitra}


Perancangansistem merupakan tahap penterjemahandarikebutuhan sistem yangdiperlukanuntuk

mempermudahpekerjaan pengguna aplikasi. Aplikasiakuntansi iniakan dirancang denganmenggunakan softwareMicrosoft Excel 2010. Tahap pertama dalam perancangan pembukuan akuntansi ini adalah menganalisis kebutuhan informasi pengguna. Kemudian tahap keduanya adalah merancang format apa saja yang akan dibutuhkan dalam menyusun laporan keuangan. Format yang akan dibuat untuk aplikasi ini adalah sebagai berikut :

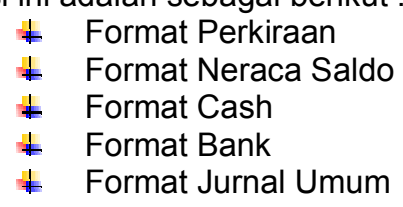

* Format Jurnal Penutup

* Format Hutang

* Format Piutang

* Format Buku Besar

* Format Neraca Lajur

* Format SHU Valuasi

* Format SHU Akumulasi

* Format Perkembangan SHU

* Format Laporan Posisi Keuangan

* Format Cash Flow

* Format Neraca Saldo Setelah Penutupan

+ Pembuatan Format Daftar perkiraan

Format iniberisitentang daftarkode akun dan nama akun yang terdapat padaKJKS-BMT.

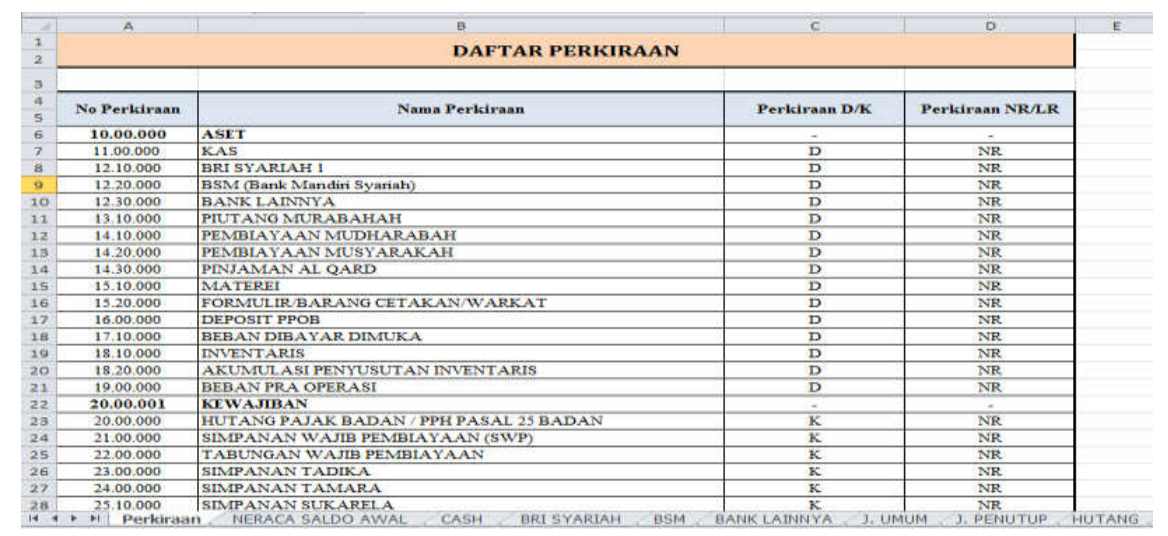

Gambar 1. Format Daftar Perkiraan

Pembuatan Format Neraca Saldo Format ini berisi tentang daftar nama akun yang terdapat pada
KJKS-BMTbeserta saldo masingmasing akun padaperiodetersebut.

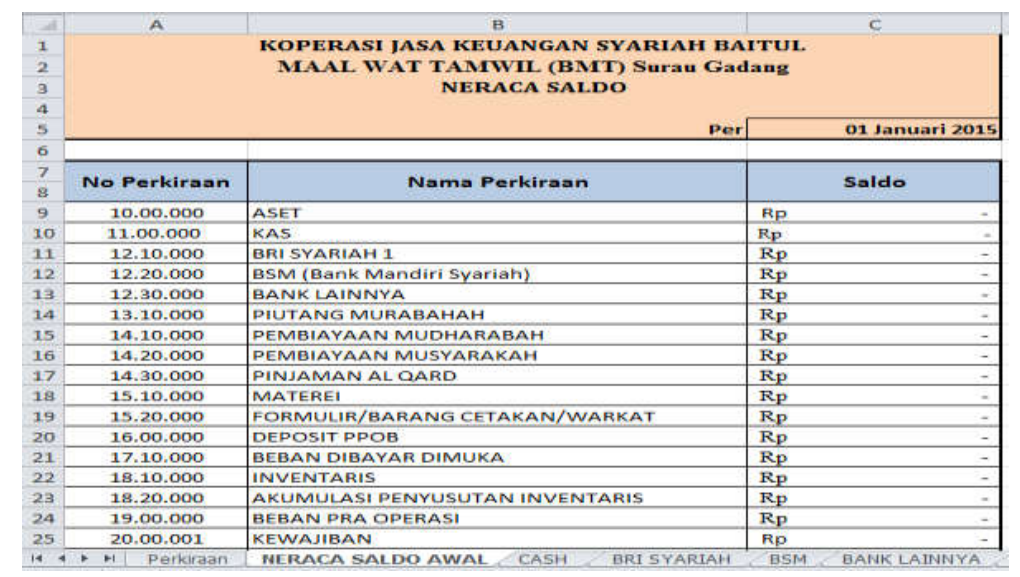




\section{Gambar 2. Format Neraca Saldo}

* Pembuatan Format Cash

Format ini berfungsi untuk merekam transaksi kasyang terjadipada KJKSBMT.

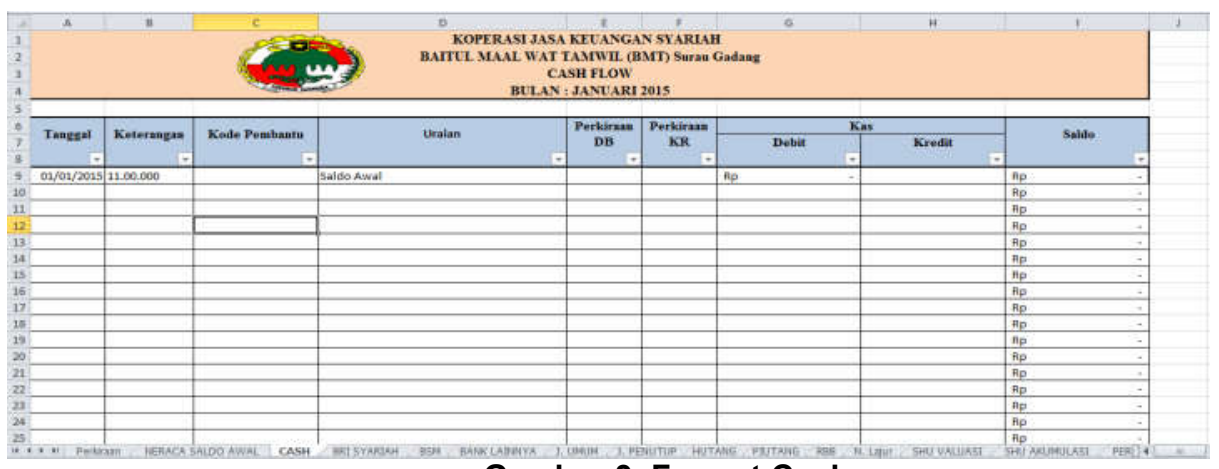

Gambar 3. Format Cash

* Pembuatan Format Bank

Format ini berfungsi untuk merekam transaksi bank yang terjadipada KJKS-BMT.

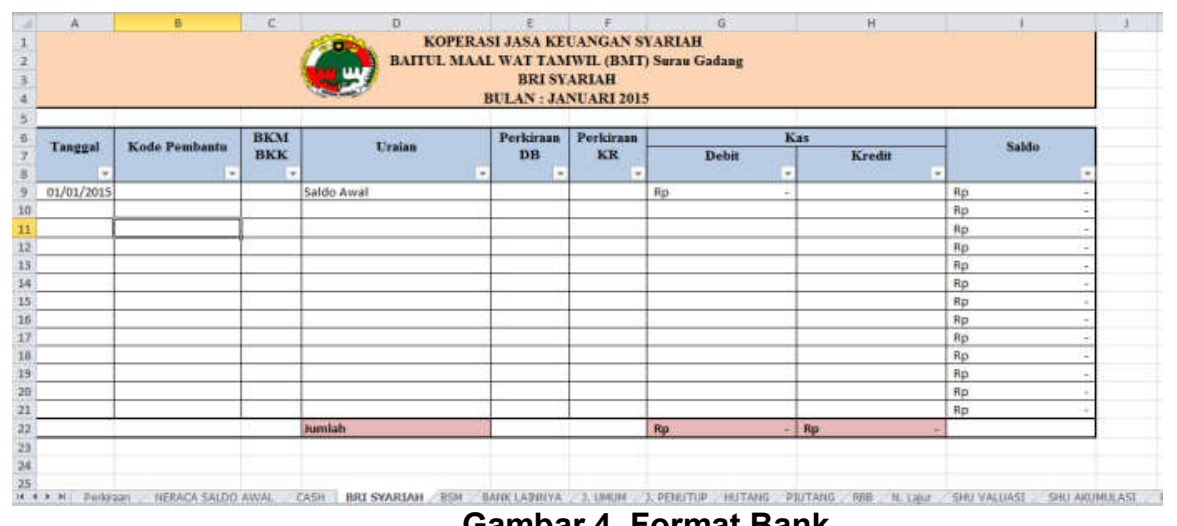

Gambar 4. Format Bank

* Pembuatan Format Jurnal Umum Format ini berfungsi untuk merekam transaksi-transaksiyang terjadipada KJKS-BMT. 


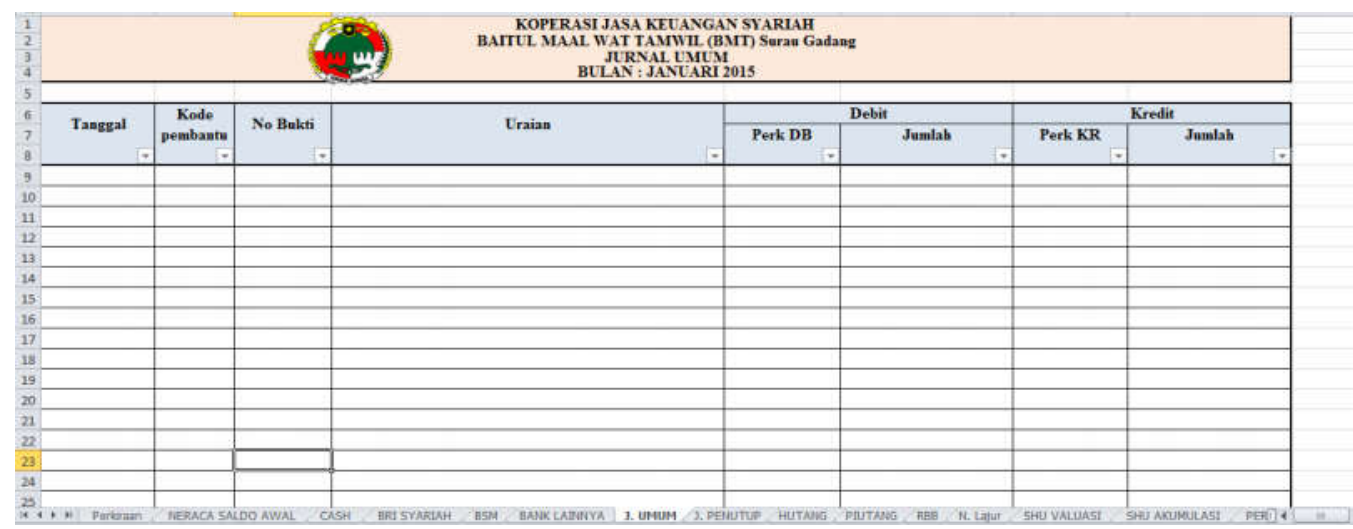

Gambar 5. Format Jurnal Umum

\& Pembuatan Format Jurnal menutupsaldo-saldo akun KJKS-

Penutup

Format

iniberfungsiuntuk

BMT

diakhirbulan.

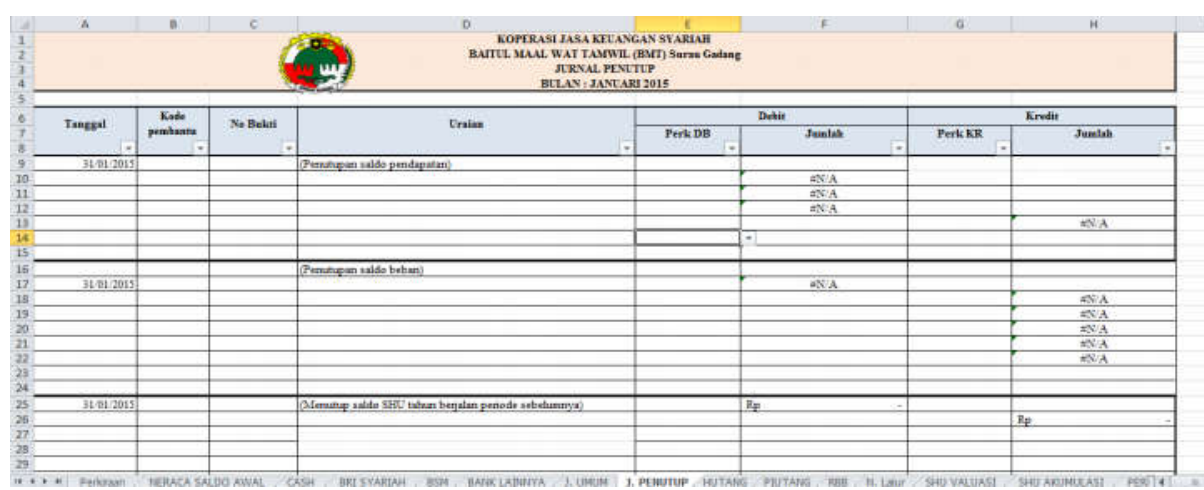

Gambar 6. Format Jurnal Penutup

Pembuatan Format Hutang

daftar saldo hutang pada KJKS-BMT

Format iniberfungsiuntuk mencatat

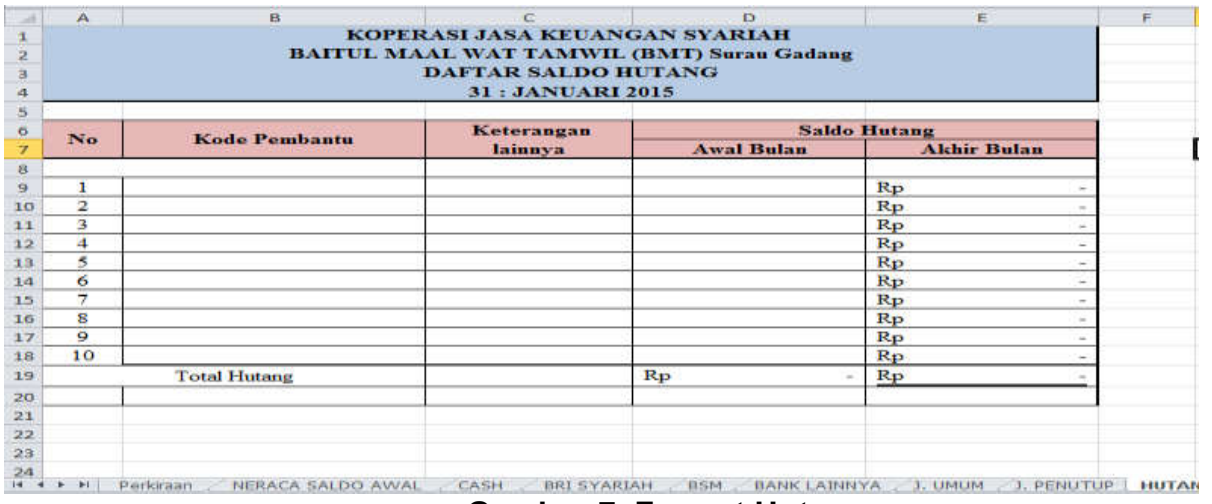

Gambar 7. Format Hutang

Pembuatan Format Piutang

Format iniberfungsiuntuk mencatat daftar saldo piutang pada KJKSBMT 


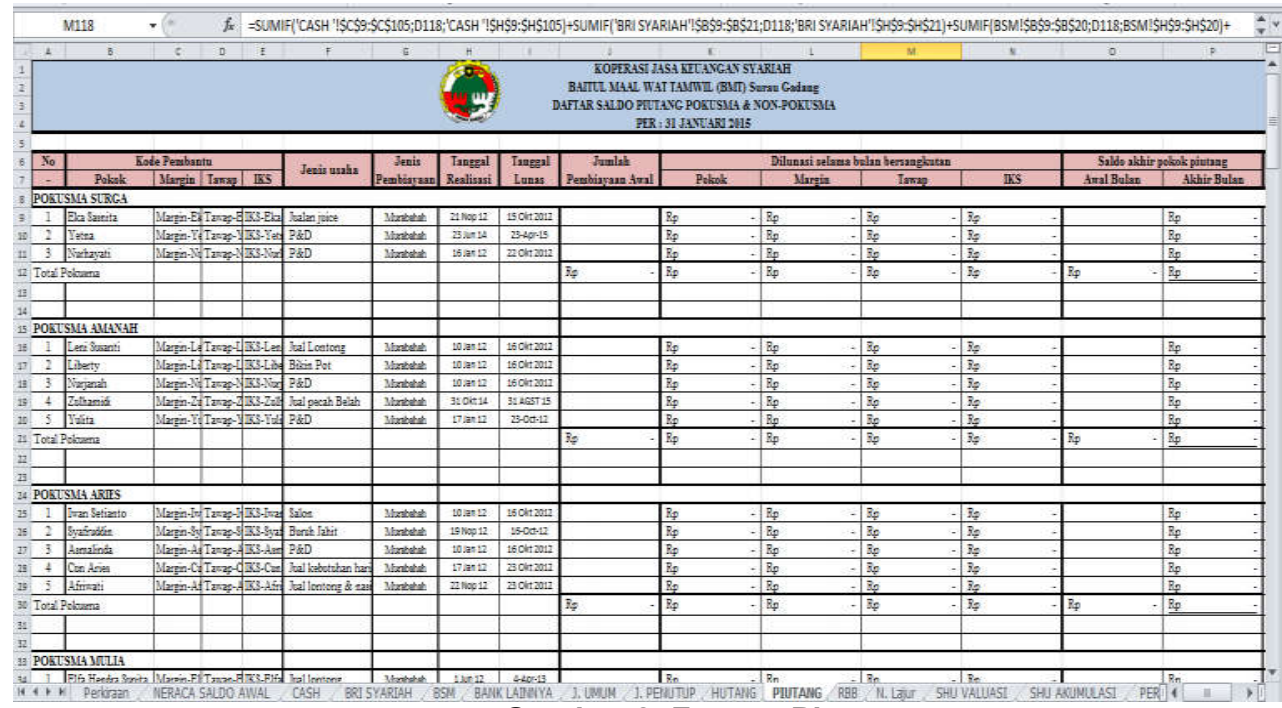

Gambar 8. Format Piutang

* Pembuatan Format Buku Besar Format iniakanmenampilkan

ringkasandaritransaksiyang telah dicatat dalam sheetjurnal.

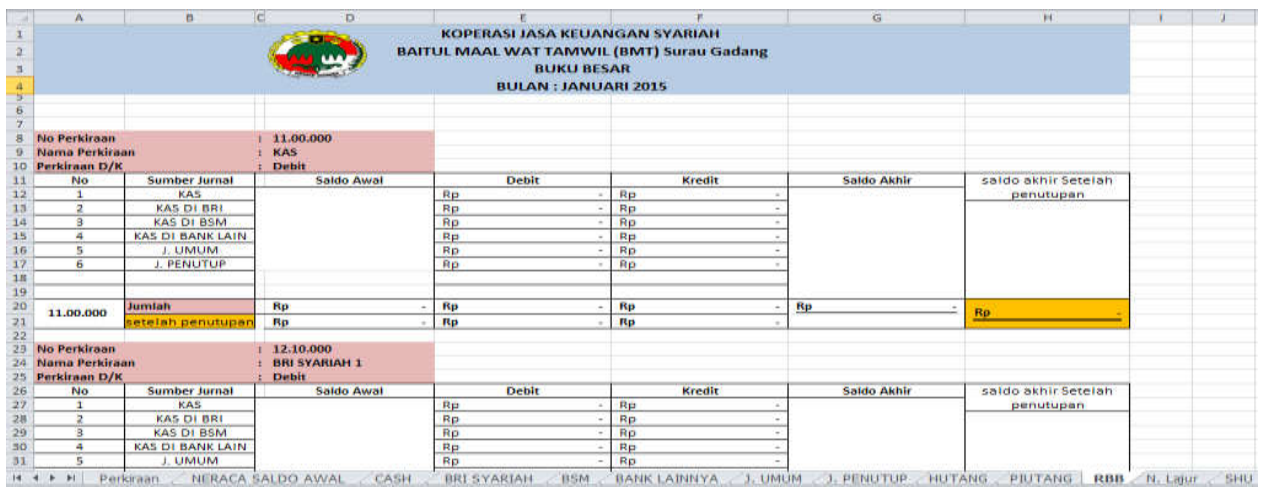

Gambar 9. Format Buku besar

* Pembuatan Format Neraca Lajur Format ini berisi ringkasan informasi yang berasal dari neraca saldo yangkemudiandilakukan penyesuaianolehpenggunalalu secara otomatiskolom NeracaSaldo Disesuaikan akanmenampilkan saldo akun yangtelah disesuaikan. 
Rancangan Pembukuan Akuntansi Berbasis Excel for Accounting

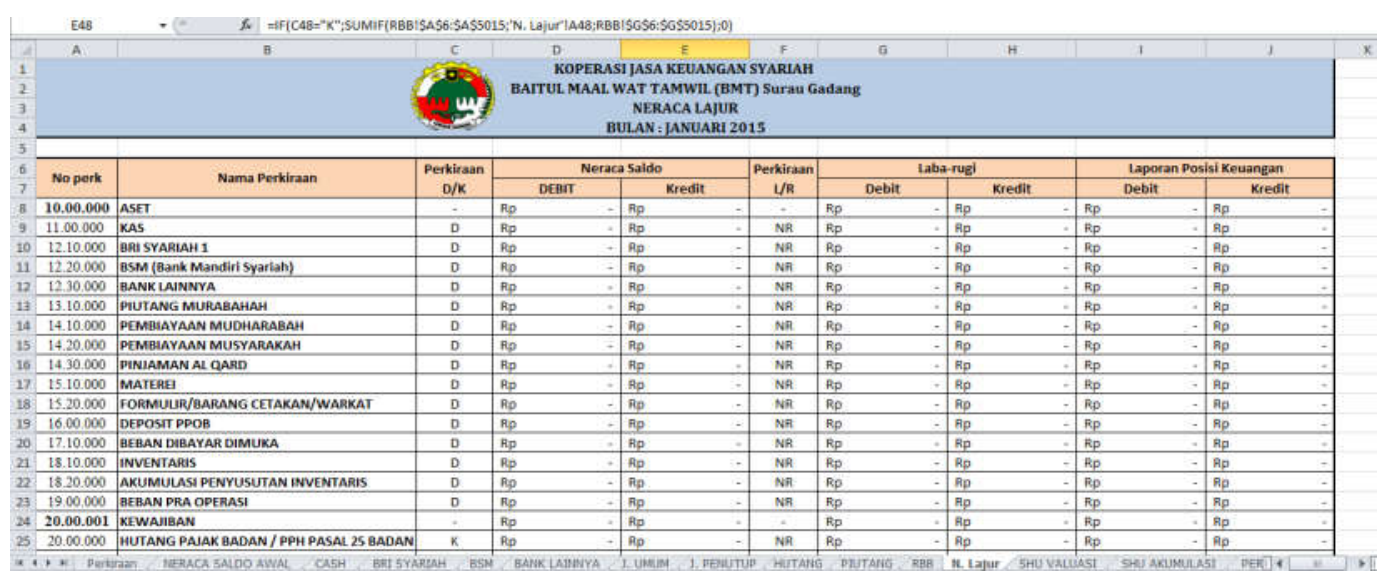

Gambar 10. Format Neraca lajur

* Pembuatan Format SHU Valuasi Format inimenyajikan informasi mengenai pendapatan dan beban

usaha KJKS-BMTselama periode tertentu.

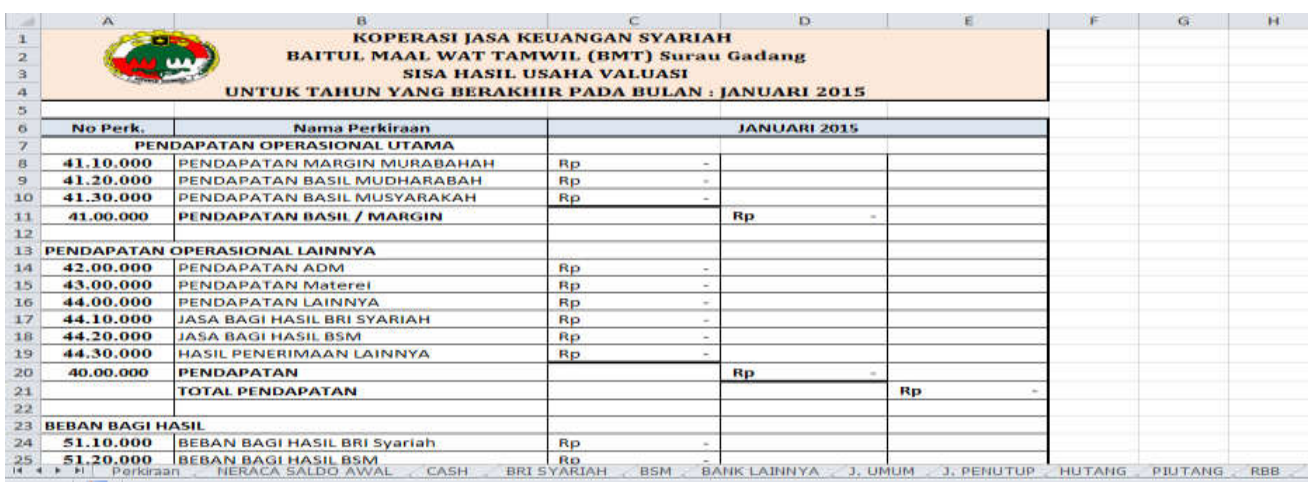

Gambar 11. Format SHU Valuasi

\& Pembuatan Format SHU $\quad \begin{aligned} & \text { mengenai akumulasi pendapatan } \\ & \text { dan beban usaha KJKS-BMTselama } \\ & \text { Akumulasi } \\ & \text { Format inimenyajikan informasi }\end{aligned}$

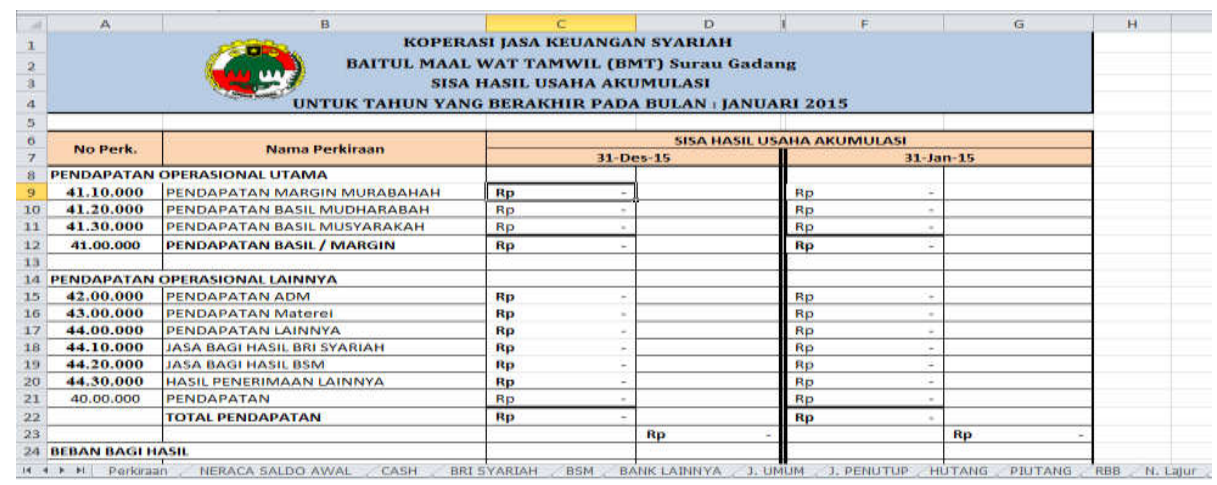

Gambar 12. Format SHU Akumulasi 
Rancangan Pembukuan Akuntansi Berbasis Excel for Accounting

* Pembuatan Format Perkembangan SHU

Format inimenyajikan informasi

perkembangan SHU KJKSBMTselama periode tertentu.

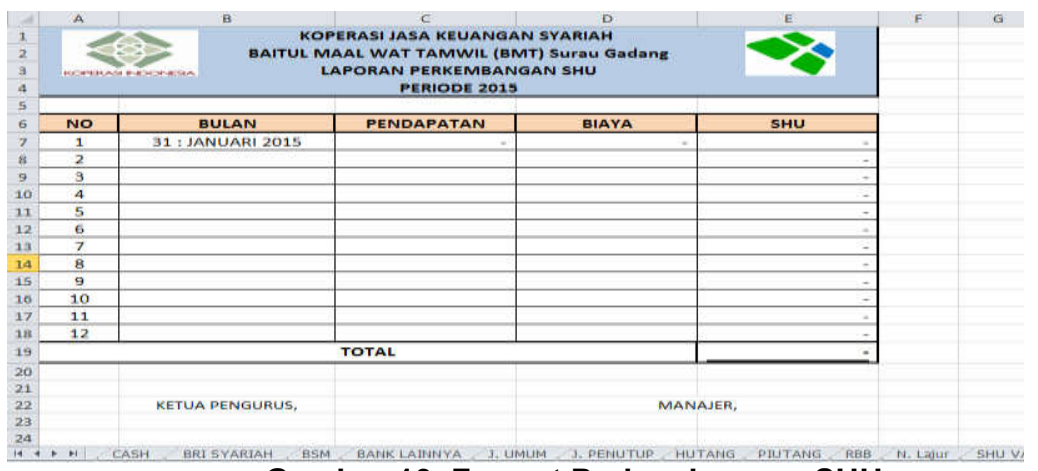

Gambar 13. Format Perkembangan SHU

* Pembuatan Format Laporan Posisi Keuangan

Format merupakanlaporanyang berisiharta,utang atau kewajiban-

kewajibanpadapihak lainbeserta modaldariKJKS-BMT selamaperiode tertentu.

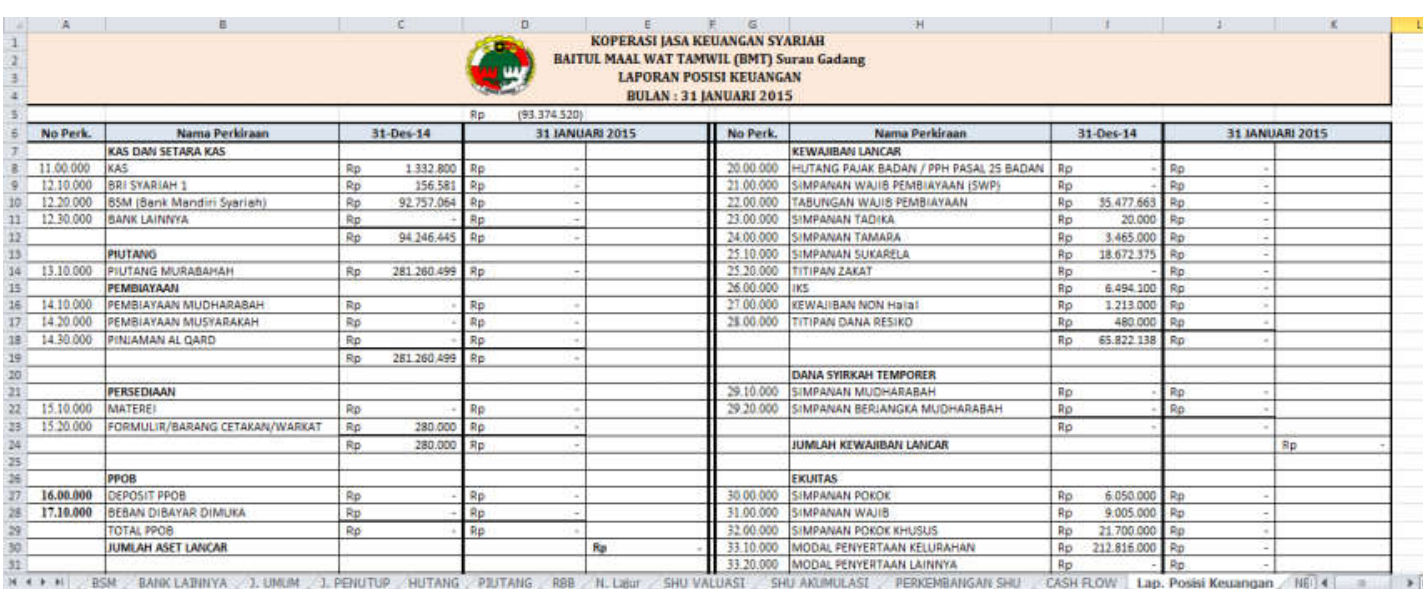

Gambar 14. Format Laporan Posisi Keuangan

* Pembuatan Format Cash Flow

Format ini merupakanlaporanyang berisialiran kasdariKJKS-BMT selamaperiode tertentu. 


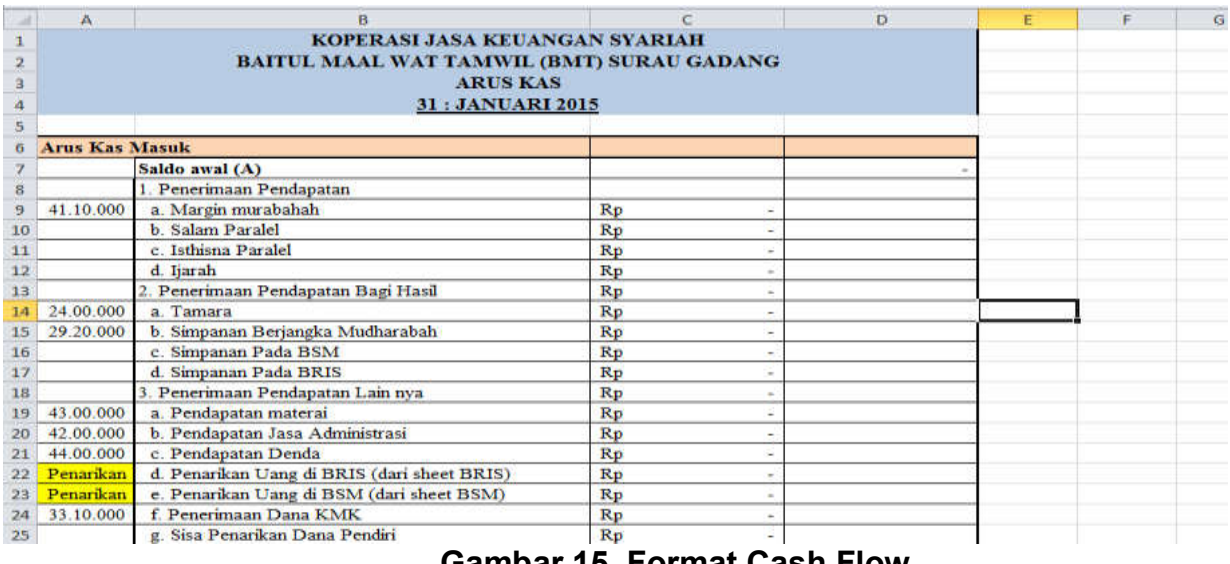

Gambar 15. Format Cash Flow

Pembuatan Format Neraca Saldo Setelah Penutupan
Format ini menutup akun-akun padaKJKS-BMT di akhir periode.

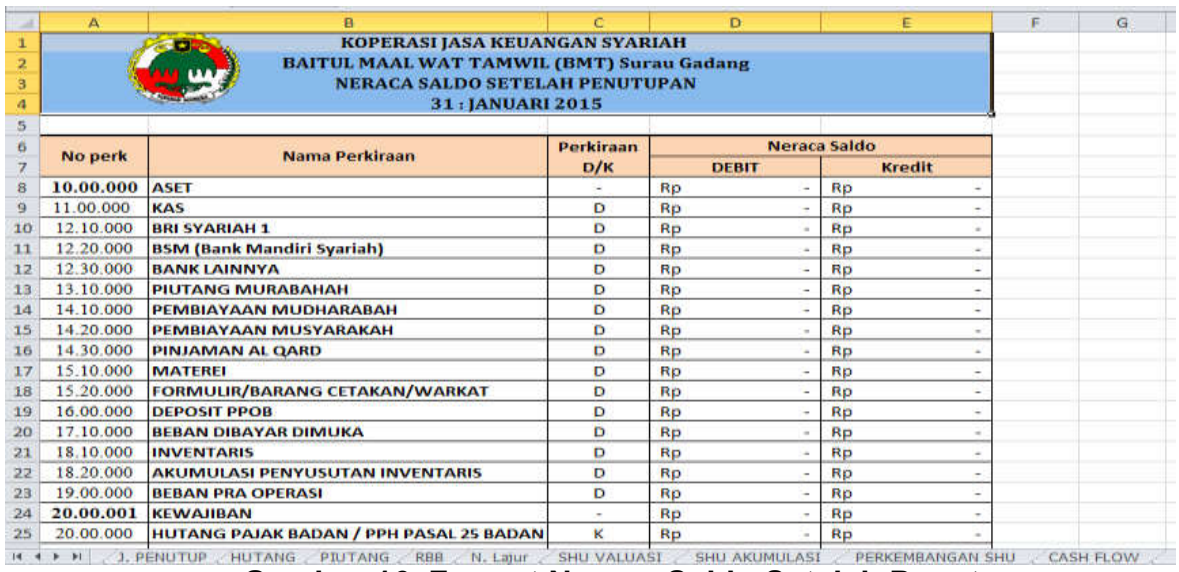

Gambar 16. Format Neraca Saldo Setelah Penutupan

\section{Luaran yang Dihasilkan}

Luaran yang dihasilkan dari kegiatan ini adalah : (1) Adanya rancangan pembukuan akuntansi berbasis excel for accounting pada kedua kelompok mitra koperasi jasa keuangan syariah. Hal ini dibuktikan dengan diberikannya software aplikasi pembukuan akuntansi berbasis excel for accounting kepada kedua mitra; (2) Adanya pengelola yaitu manajer dan bagian pembukuan dari kelompok mitra koperasi jasa keuangan syariah ini yang memiliki kemampuan dalam mengoperasikan database keuangan yang sudah dibuat. Hal ini dibuktikan dengan diberikannya "Modul Panduan Penyusunan Laporan Keuangan KJKS"; (3) Adanya pengelola yaitu manajer dan bagian pembukuan dari kelompok mitra koperasi jasa keuangan syariah ini yang memiliki kemampuan dalam menganalisa dan menginput transaksi keuangan pada rancangan aplikasi yang dibuat. Hal ini dibuktikan dengan diberikannya "Modul Panduan Penyusunan Laporan Keuangan KJKS". Didalam modul panduan ini kita menjelaskan tentang bagaimana cara mengoperasikan rancangan aplikasi yang dibuat serta panduan dalam menginput transaksi keuangan sehingga menghasilkan laporan keuangan KJKSBMT; (4) Pengelola bisa mendapatkan informasi keuangan yang terkini setiap saat dengan mengakses aplikasi yang dibuat. 


\section{KESIMPULAN DAN SARAN}

\section{Kesimpulan}

Dari hasil observasi yang telah dilakukan kepada kedua mitra KJKS-BMT baik lewat pengamatan dan wawancara dapat diidentifikasi masalah yang muncul. Berdasarkan kunjungan dan wawancara yang telah dilaksanakan dengan mitra tersebut, dapat disimpulkan bahwa mitra belum memiliki program pembukuan yang memadai untuk memenuhi kebutuhan akan pelaporan keuangan yang baik (sesuai standar akuntansi); mitra belum memiliki kompetensi yang cukup menganalisis transaksi keuangan dan menyusun laporan keuangan; mitra memerlukan pelatihan yang memadai mengenai analisis transaksi, menjurnal transaksi dan menyusun laporan keuangan yang sesuai dengan standar akuntansi; mitra memerlukan perangkat hardware dan software program pembukuan akuntansi. Hardware berupa perangkat komputer dan printer untuk mencetak laporan, sedangkan software adalah aplikasi program pembukuan akuntansi yang dibuat dengan Microsoft Excel dengan tujuan agar mudah digunakan dan gampang untuk dilakukan perawatan (maintenance) di kemudian hari; mitra memerlukan pengetahuan dan keterampilan yang memadai untuk memperbaiki manajemen dengan tujuan untuk mampu bersaing dan meningkatkan omzet penjualan jasa yang ditawarkan.

\section{DAFTAR PUSTAKA}

Arifin, Johar. (2006).Komputer Akuntansi dengan Microsoft Excel, Elexmedia Komputindo, Jakarta.

Artikel Pengertian KJKS BMT.Diakses tanggal $26 \quad$ April 2014. http://www.ussisulsel.com.

DP2M Dikti. (2013).Panduan Pelaksanaan Penelitian dan PPM Edisi-IX -2013, Jakarta : Ditjen Kemendikbud..

Kusrianto, Adi. (2000).Mengupas Tuntas Formula dan Fungsi Microsoft Excel, Elexmedia Komputindo, Jakarta.

Pemko. (2010). Panduan Umum Program Penanggulangan Kemiskinan Berbasis Kelurahan Melalui Pengembangan KJKS BMT,Badan Pemberdayaan Masyarakat dan Pemerintah Kelurahan Kota Padang.

Syarifuddin. (2004).Program Aplikasi Akuntansi dengan Microsoft Excel, Qowamedia Utama, Solo.

Soemarso, SR. (2004).Akuntansi Suatu Pengantar, Salemba, Jakarta.

Weygandt, Jerry J, Kieso, Donald E., dan, Kimmel,Paul D. (2011).Financial Accounting, IFRS Edition, John Wiley and Sons. 